\title{
Early Versus Late Fixation of Mandibular Fractures in Adults
}

\author{
Osama A. Alshahhat, Mahmoud A. Amin, and Ahmed M. Safwat
}

\author{
Department of Plastic Surgery, Faculty of Medicine, Al-Azhar University \\ *Corresponding author: Osama Abd Elraheem Alshahhat, E-Mail: osamaalshahat@yahoo.com, Mobile: 01223311901
}

\begin{abstract}
Background: facial fractures occur most commonly in males in the third decade of life. The most frequent causes of facial fractures are road traffic accident, interpersonal violence, falls, and sportsrelated accidents. Mandible fractures are one of the common facial fractures in the adult population. However, the timing of treatment of mandible fractures remains a source of debate.

Aim of the work: the aim of the study was to evaluate the effectiveness of early versus late treatment of isolated mandibular fractures in adults upon healing and postoperative complications.

Patients and Methods: the present study included 20 patients who were presented by isolated mandibular fractures. They were divided into two groups according to the time utilized from injury to operative intervention: Group 1: included 11 patients who were treated within 72 hours. Group 2: included 9 patients who were treated after 72 hours up to 14 days. All included patients were underwent full history taking, examinations (general and local) done in a systematic manner, laboratory and radiological examination. Outcome was documented for all patients.

Results: both groups were comparable as regard to age and sex (no females). The most common cause of trauma in studied patients was road traffic accident. Operative time extended from 110 to 192 minutes with no significant difference between absorbable and non-absorbable groups $(150.07 \pm 23.99$ vs $160.06 \pm 20.54$ minutes respectively). There were a total of 20 males and no females in the study group with a mean age of $23.3 \pm 6.3$ (range 18to 38 years) in the immediate group and $26.6 \pm 8.1$ (range 18 to 39 years) in the delayed group. The most common fracture types in both groups were parasymphyseal and angle fractures with RTA as the most common etiology. In the immediate group, there were one patient with temporomandibular joint pain after surgery, five patients with numbness, and one patient with malocclusion. In the delayed group, no patients with TMJ pain, seven patients with numbness, and two patients with malocclusion.

Conclusion: our study did not reveal a statistically significant difference in the development of postoperative complications after mandible fracture repair between the early and late treatment groups. Keywords: Complications, delayed treatment, mandibular fracture
\end{abstract}

\section{Introduction}

Facial fractures occur most commonly in males in the third decade of life. The most frequent causes of facial fractures are road traffic accidents, interpersonal violence, falls, and sports-related accidents. Their prevalence is geographically dependent. Road traffic accidents are the most common cause of facial fractures all over the world. Nasal fractures are the most common, followed by dentoalveolar and mandibular fractures, mid face and orbital floor fractures, and then frontal sinus ${ }^{(\mathbf{1})}$.

Mandibular fractures are one of the common facial fractures in the adult population. However, the timing of treatment of mandible fractures remains a source of debate. All mandibular fractures through the dentoalveolar areas are open fractures because of the potential for communication through the periodontal ligament space. Although some clinicians propose that mandibular fractures benefit from immediate care, others prefer to delay treatment, especially if faced with difficult logistics in obtaining operating room time ${ }^{(2)}$.

Airway compromise and hemorrhage are indications for acute reduction. In mandibular fractures, delaying repair may increase bacterial count and osseous devascularization, so early immobilization is recommended ${ }^{(\mathbf{1})}$.

Fractures can be classified as favorable or unfavorable based on the stability afforded by the pull of muscles on the fractured segments of bone. The temporalis and masseter muscles exert the primary upward force while the downward force is exerted by the suprahyoid musculature and gravity. If these forces act to bring the fracture line together, the fracture is favorable; if they act to pull the fracture line apart, the fracture is unfavorable. Following callus formation of non-reduced mandibular 
fractures, reconstruction becomes a surgical challenge requiring complex procedures as osteotomies and/or onlay grafts. Primary repair usually offers best functional recovery as well as easier repair ${ }^{(2)}$.

The most common complication after mandibular fracture is postoperative infection. Other postoperative complications are in the form of mandibular nonunion and malunion, malocclusion, soft tissue dehiscence, and TMJ dysfunction ${ }^{(5)}$.

\section{Aim of the study}

The aim of the study is to evaluate the effectiveness of early versus late treatment of isolated mandibular fractures in adults upon healing and postoperative complications hospitalization and medication cost.

\section{Patients and Methods}

The present study was conducted at the Plastic Surgery department; Al-Azhar University hospitals (Cairo, Damietta) and Damietta Military Hospital. It included 20 patients who were presented by isolated mandibular fractures. They were divided into two groups according to the time utilized from injury to operative intervention.

Group 1: included 11 patients who were treated within 72 hours (Early group). Group 2: included 9 patients who were treated after 72 hours up to 14 days (Late group).

The study protocol was approved by local Ethical Committee of Al-Azhar Faculty of Medicine. In addition, all patients or their guardians were informed about the study and their consent for participation in the study was obtained. Patient right to withdrawal at any time was ascertained.

Inclusion criteria: patients fulfilling the following were included in the study: Adult age (18-40) years and free from other specialties.

Exclusion criteria: patients with one or more the following were excluded from the study: Pediatric fracture, associated comorbidities, edentulous patients, fractures more than 2 weeks, Pan-facial fractures and Condylar fractures.

All included patients were underwent full history taking, examinations (general and local) done in a systematic manner. Any steps or irregularities along the bony margin are suggestive of a fracture. Inspect oral cavity for lost teeth, lacerations, occlusal alterations, step deformities, and inability to open the mouth properly. Finally, laboratory and radiological investigations were done according to clinical situation. Medical photography was obtained before, intraoperative and postoperative at 1,2 and 4weeks.

\section{Statistical methods:}

Data entry and statistical analyses were performed using SPSS (statistical package of social sciences) version 21 (SPSS Inc., Chicago, IL, USA). Categorical data were expressed in number and percentage. Continuous normally distributed data were expressed in mean and standard deviation.

Independent sample $\mathrm{T}$ test was used for continuous normally distributed data. To study the association between Categorical data chi square test was used. Statistical significance was considered when probability $(\mathrm{P})$ value was less than or equal to 0.05 .

\section{Results}

In the present work, 20 patients were included; all were males. Age of studied patients ranged from 18 years to 39 years; the mean age was $23.3 \pm 6.3$ (range 18 to 38 years) in the immediate group and 26.6 \pm 8.1 (range 18 to 39 years) in the delayed group. The most common cause of trauma in studied patients was road traffic accident reported in 17 out of 20 subjects $(85 \%)$, then fall from height in 2 subjects (10\%) and finally physical assault in 1 subject $(5 \%)$, and there was no significant difference between studied groups.

As regard to site of fracture, in the early group it is right in $3(27.3 \%)$, left in $3(27.3 \%)$ and bilateral in $5(45.5 \%)$. In the late group it is right in $0(0 \%)$, left in $1(11.1 \%)$ and bilateral in $8(88.9 \%)$. According to distribution of fracture, in the early group, angle fracture was in $3(27.3 \%)$, parasymphyseal in $3(27.3 \%)$, parasymphyseal-body in 2 (18.2\%), Bodyangle in $0(0 \%)$, Parasymphyseal-angle in 2 $(18.2 \%)$, Body in $1(9.1 \%)$. In the late group, angle fracture was in $0(0 \%)$, parasymphyseal in $1(11.1 \%)$, parasymphyseal-body in 4 (44.4\%), Body-anglein 2 (22.2\%), Parasymphyseal-angle in $1(11.1 \%)$ and Body 1 $(11.1 \%)$ (Table 1). As regard to intraoperative reduction and fixation, in the early group, it was easy in $11(100 \%)$. In the late group, it was easy in $2(22.2 \%)$, difficult in $6(66.7 \%)$ and average in $1(11.1 \%)$. According to occlusion, in the early group, there was one case of malocclusion 
$1(9 \%)$ and three cases in the late group 3 $(33.3 \%)$. Union was good in all cases in the early and late groups Table (2). Other postoperative complications were in the form of TMJ dysfunction in $1(9.1 \%)$ in the early group.
Numbness was reported in $5(45.5 \%)$ in the early group and $7(77.8 \%)$ in the late group. There were no cases of post-operative infection in both groups; Table (3).

Table (1): demographic characteristic of the study

\begin{tabular}{|c|c|c|c|}
\hline Variable & Early (N=11) & Late (N=9) & p \\
\hline Age & $23.3 \pm 6.3$ & $26.6 \pm 8.1$ & 0.317 \\
\hline Site of fracture & \multicolumn{3}{|c|}{$0.039^{*}$} \\
\hline Right & $3(27.3)$ & $0(0)$ & \\
\hline Left & $3(27.3)$ & $1(11.1)$ & \multirow{2}{*}{0.231} \\
\hline Bilateral & $5(45.5)$ & $8(88.9)$ & \\
\hline Angle & $3(27.3)$ & $0(0)$ & \\
\hline Parasymphyseal & $3(27.3)$ & $1(11.1)$ & \\
\hline Parasymphyseal-body & $2(18.2)$ & $4(44.4)$ & \\
\hline Body-angle & $0(0)$ & $2(22.2)$ & \\
\hline Parasymphyseal-angle & $2(18.2)$ & $1(11.1)$ & \\
\hline Body & $1(9.1)$ & &
\end{tabular}

Table (2): post-operative evaluation

\begin{tabular}{|c|c|c|c|c|}
\hline \multicolumn{2}{|c|}{ Variable } & Early $(\mathrm{N}=11)$ & Late $(\mathrm{N}=9)$ & $\mathrm{p}$ \\
\hline \multirow{2}{*}{ Occlusion } & Normal & $10(91)$ & $6(66.6)$ & \multirow{2}{*}{0.104} \\
\cline { 2 - 4 } & Abnormal & $1(9)$ & $3(33.3)$ & \\
\hline \multirow{2}{*}{ Reduction-fixation } & Easy & $11(100)$ & $2(22.2)$ & \multirow{2}{*}{$0.001^{*}$} \\
\cline { 2 - 4 } & Difficult & $0(0)$ & $6(66.7)$ & \\
\cline { 2 - 4 } & Average & $0(0)$ & $1(11.1)$ & \\
\hline Union & Good & $11(100)$ & $9(100)$ & 1 \\
\hline
\end{tabular}

Table (3): post-operative complications

\begin{tabular}{|c|c|c|c|c|}
\hline \multicolumn{2}{|c|}{ Variable } & Early $(\mathrm{N}=11)$ & Late $(\mathrm{N}=9)$ & $\mathrm{p}$ \\
\hline \multirow{2}{*}{ TMJ dysfunction } & Yes & $1(9.1)$ & $0(0)$ & \multirow{2}{*}{0.366} \\
\cline { 2 - 4 } & No & $10(90.9)$ & $9(100)$ & \\
\hline Post operative infection & No & $11(100)$ & $9(100)$ & 1 \\
\hline \multirow{2}{*}{ Numbness } & Yes & $5(45.5)$ & $7(77.8)$ & \multirow{2}{*}{0.152} \\
\cline { 2 - 4 } & No & $6(54.5)$ & $2(22.2)$ & \\
\hline
\end{tabular}

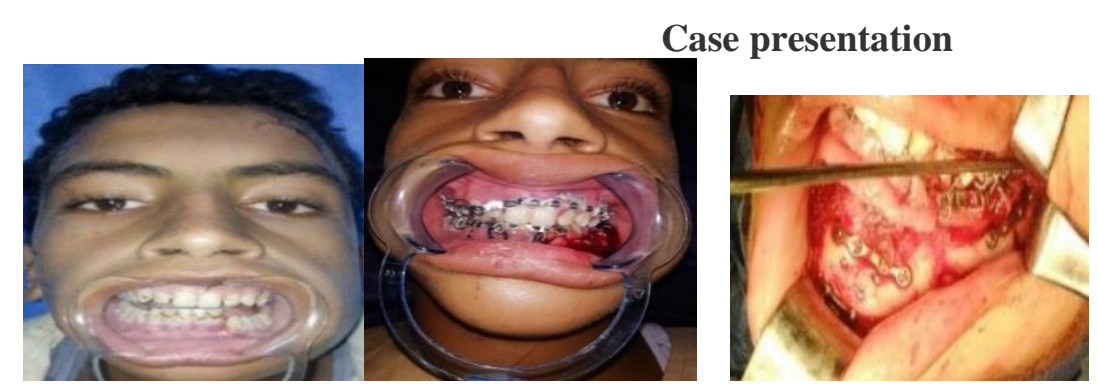

(a)

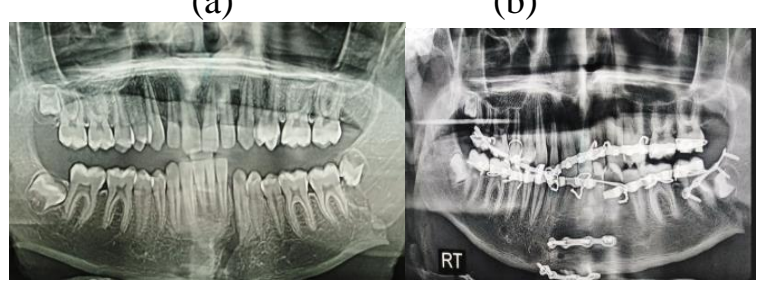

(d) (c)

Figure (1): A male patient 21 years old with left parasymphyseal, left angle fracture (a) Preoperative clinical anterior view (b) postoperative clinical anterior view (c) Intraoperative view showing fixation of the left parasymphyseal, left angle fracture of the mandible with titanium plates and screws. (d) 
Panoramic view showing preoperative fracture of the mandible and one week (e) postoperative fixation using titanium plates and screws.

\section{Discussion}

An established time for repair of mandible fractures as a standard of care has not been firmly established by the treating specialties. Treatment practices related to the timing of repair seem to be associated with patient compliance, the doctor's clinical judgment, and logistics. This has been, in part, because the published data are without a study specified to the matter. In general, the findings of complications associated with the timing of fracture repair have been elaborated within the research of other associated topics. Thus, topics such as early immobilization, infection incidence, patient compliance, substance abuse, problems associated with teeth within the line of fracture, and compound injuries have been studied as isolated variables, within the context of postoperative complications ${ }^{(8)}$.

We recommend early fixation of mandibular fractures for these reasons. The continuous increased number of admitted cases of maxillofacial trauma in Al-Azhar University Hospital (New Damietta) is due to its geographical location near the international Coastal high way and presence of the industrial zone. Another reason is the remarkable decrease in the overall cost of hospital stay. In the early group, the average hospital stay was 3 to 5 days whereas it was 7 to 16 days in the late group which definitely affects the hospital resources as drugs, nursing care and occupying inpatient beds which may be needed for urgent cases. The early return to the work is another consideration .Finally, the slightly greater percentage of complications noted for the late group suggests that prompt treatment is a safe clinical instinct.

Our study was designed to compare between early and late fixation in mandibular fractures. Twenty patients qualified for the present prospective study based on exclusion criteria. Eleven patients were repaired within 72 $h$ of the injury (Early group) while the remaining 9 were repaired after $72 \mathrm{~h}$ of the inciting event (delayed group). There were a total of 20 males and no females in the study group which is not explained with a mean age of $23.3 \pm 6.3$ (range 18 to 38 years) in the immediate group and $26.6 \pm 8.1$ (range 18 to 39 years) in the delayed group. The most common fracture types in both groups were parasymphyseal and angle fractures with RTA as the most common etiology.

Mean time to repair for the immediate group was 2.27 (range one to three days) versus 9.7 days (range 4 to 14 days) for the delayed group. Webb et al. ${ }^{(13)}$ reported in his study that Mean time to repair for the immediate group was one day (range one to three days) versus 8.8 days (range four to 27 days) for the delayed group.

In terms of postoperative complications, a follow up of 4 weeks was recorded. No patients reported post-operative infection. For sure, prior studies have shown an association between prior treatment and diminished disease. Anderson and Alpert ${ }^{(1)}$ displayed a $16 \%$ overall postoperative infection rate in a study of 75 mandible fractures, but no infections occurred in patients treated within 24 $\mathrm{h}$ of injury ${ }^{2}$.

An alternate study by Maloney et al. ${ }^{(9)}$ reported 204 fractures in 131 patients with overall infection rate of $4.4 \%$. In any case, consistent patients treated within $72 \mathrm{~h}$ of injury and or trauma had no contaminations and infections.

We propose that absence of postoperative infection in our study is based on the exclusion criteria such as age which was limited from 18 to 40 years, absence of coincident comorbidity as diabetes and absence of other facial fractures.

Regarding other post-operative complications as TMJ dysfunction, numbness and malocclusion, our study revealed one patient with temporomandibular joint pain after surgery, five patients with numbness, and one patient with malocclusion (posterior open bite on the fracture site) in the early group. In the delayed group, no patients with TMJ pain, seven patients with numbness, and three patients with malocclusion (two posterior open bite ad one anterior open bite).

The study by Webb et al. ${ }^{(13)}$ was quite similar to our study. They reported three patients with temporomandibular joint pain after surgery, and two patients with malocclusion in a total of seventeen cases of the immediate group. On the other hand, there was one patient with temporomandibular joint pain after surgery, two patients with persistent 
malocclusion and were referred to oral surgery for further management.

Another important consideration in managing patients with a mandible fracture is determining a cost-effective treatment algorithm. Stable patients with mandible fractures who can feed orally and who display no airway compromise can be managed as outpatients and scheduled as elective cases. We agree with David et al. ${ }^{(4)}$ regarding patients admitted from the emergency department for immediate repair were often postponed due to operating room delays for lack of personnel or more acute cases taking priority from other specialties. This leads to more prolonged hospital admissions and increased costs. Elective treatment allows for a shorter hospital stay as well as use of ambulatory surgical facilities, which can be more cost-effective than performing surgery at a tertiary care centre.

\section{Conclusion}

Our study did not reveal a statistically significant difference in the development of a postoperative complication after mandible fracture repair between the early and late treatment groups. However, the slightly greater percentage of complications noted for the late group suggests that prompt treatment is a safe clinical instinct.

\section{References}

1. Anderson $T$, Alpert B (1992): Experience with rigid fixation of mandibular fractures and immediate function. J Oral Maxillofac Surg., 50:555-60.

2. Biller J, Pletcher S, Goldberg AN et al. (2005): Complications and the time to repair of mandible fractures. Laryngoscope, 115:769.

3. Czerwinski M, Parker WL, Correa JA, Williams HB (2008): Effect of treatment delay on mandibular fracture infection rate. Plast Reconstr Surg., 122:881-5.

4. David LR, Bisseck M, Defranzo A, Marks M, Molnar J, Argenta LC (2003): Cost-based analysis of the treatment of mandibular fractures in a tertiary care center. J Trauma Inj Infect Crit Care, 55:514-7.

5. Furr AM, Schweinfurth JM and May WL (2006): Factors associated with long-term complications after repair of mandibular fractures. Laryngoscope, 116:427.

6. Halicioglu K, Celikoglu M, Buyuk SK, Sekerci AE, Candirli C (2014): Effects of early unilateral mandibular first molar extraction on condylar and ramal vertical asymmetry. Eur $\mathbf{J}$ Dent.,8:178-83

7. Malanchuk VO and Kopchak AV (2007): Risk factors for development of infection in patients with mandibular fractures located in the tooth-bearing area. J Craniomaxillofac Surg., 35:57.

8. Maloney PL, Lincoln RE, Coyne CP (2001): A protocol for the management of compound mandibular fractures based on the time of injury to treatment. J Oral MaxillofacSurg., 59:879,

9. Maloney PL, Welch TB, Doku HC (1991): Early immobilization of mandibular fractures: A retrospective study. J Oral Maxillofac Surg .,49:699,

10. Neal D, Wagner W, Alpert B (1978): Morbidity associated with teeth in the line of mandibular fractures. J Oral Surg., 36:859,

11. Pham-Dang N, Barthélémy I, Orliaguet T, Artola A, Mondié JM, Dallel R (2014): Etiology, distribution, treatment modalities and complications of maxillofacial fractures. Med Oral Patol Oral Cir Bucal, 19:e261-9.

12. VandeGriend ZP, Hashemi $A$ and Shkoukani M (2015): Changing trends in adult facial trauma epidemiology. J CraniofacSurg., 26:108-12.

13. Webb LS, Makhijani S, Khanna M (2009): A comparison of outcomes between immediate and delayed repair of mandibular fractures. Can J Plast Surg., 17(4):124-126. 